\title{
Social Concerns for the Industrialization of Regional Culture in
}

\section{Gansu*}

\author{
XU Guo-zhu \\ Northwest Normal University, Lanzhou, China
}

\begin{abstract}
Gansu, as the birthplace of Chinese Civilization, has very rich cultural resources. The advantages of regional culture in Gansu are strongly inclusive in category, excellent in spirit, rare in resources, completely worthless in value, famous world-wide, and so on. But serious concerns still exist in the industrialization of regional culture in Gansu, China. Here we recall the advantages of the cultural resources in this province, since it is beneficial for training a kind of cultural spirit or consciousness. It is also intended to put forward suggestions for the industrialization of regional culture and avoid unnecessary steps or even irretrievable loss.
\end{abstract}

Keywords: social concerns, industrialization, regional culture

\section{Introduction}

Nowadays, more and more attention has been paid to the industrialization of regional culture in China, but most of its products are imitations because of economy, techniques, talents, and other reasons. Since 1980s the governments at different levels have begun to realize the importance of its industrialization and discuss over the vestment in this field. It is inevitable that its design features do not focus on its local characteristics, which cannot have any impact on the local economy. Many factors are contributory to this result. Objectively, the industrialization of regional culture is weak in China; subjectively, its design falls behind with poor design language. The fundamental reason for failure is the lack of design philosophy with Chinese characteristics, which could especially show the features of a certain regional culture. Thus, what we should do is to learn the successful experience from the West, instead of simple plagiarism. The design should be local, sustainable, and economically effective. Let us have a case study about the industrialization of regional culture in Gansu, China.

\section{Cultural Traits of Gansu}

Gansu Province is rich in cultural resources. It is one of the largest provinces with cultural relics because of regional distribution, amount of unearthed, and quality of preservation. According to the latest data, there are 137 historical relics in Gansu, with 17,854 unmovable treasures and 1,750 state-owned collections. On line of protection level, Gansu owns two World Heritage sites, 72 state-emphasis cultural relic units, and 526 provincial ones, which are among the highest in China. Besides, 61 items, such as "Hua'er (Flower)" and "Tibetan Opera", were listed in World Nonmaterial Cultural Heritage List. There are also many national red

\footnotetext{
* Acknowledgements: This research is supported by the University Scientific Research Project of Gansu (A Study on the Industrialization of Regional Culture in Gansu: Sec. 5003/No. 1030).

XU Guo-zhu, associate professor, M.A., English Department, Foreign Languages College, Northwest Normal University, Lanzhou, China.
} 
classic scenic areas, national famous scenic areas, state historical and cultural cities, historical famous towns and villages, etc. (TIAN, 2013). By the types of their cultural identity, the historical and cultural resources consist of three main types: source of Chinese Civilization, Silk Road Culture, and the folklore of multiracial and multicultural society. With such a rich resource, the development and industrialization of Gansu brought about wide social concerns.

\section{Problems of Industrialization in Gansu}

\section{Mismatching of Resources and Their Value}

It is necessary for the local governments to build up a scientific research system for the full accomplishment of the industrialization of reginal cultural resources (HUANG, 2014). It aims at having a reasonable development and utilization of these resources according to their value, avoiding unnecessary drainage on manpower and material resources. At present, Gansu falls behind in the understanding of cultural resources, protection, and utilization. It is urgent for Gansu to make a massive screen for an early diagnosis of cultural resources. The purpose is to form a complete system of cultural resources. On the other hand, Gansu has few opportunities to communicate with others, so few technicians and investors pay attention to its development requirements. In the result, many potential values in its regional cultural disappear day by day. In a word, the sustainable development of reginal culture in Gansu depends on a valuable utilization of its cultural resources.

\section{Lacking Talents for Cultural Industrialization}

Talents are the key factors for the development of cultural industrialization. They are responsible for research, design, management, marketing, and investment. The lack of any talents hinders the development of cultural industrialization. The main problems in Gansu are: The lack of senior talents affects the integration of cultural and financial capitals and the determination of marketing, propaganda, popularization, etc. The managers with poor quality in this field lay more stress on the profits instead of the true value of culture. In a large degree, the lack of people with high-tech skills will hold back the development of our economy. So, it is difficult for Gansu to exploit scientific and more acceptable cultural products.

\section{Being Short of Projects to Attract Investment}

Another main problem, which restricts the industrialization of regional culture in Gansu, is short of influential project. Although Gansu is famous for Mo Kao Grotto at Dunhuang, Fuxi (the first Chinese ancestor), and so on, the development and propaganda have been done only at spiritual level. With no tangible products and service, it is impossible to create a derived consumer market in Gansu. In a word, the influential and massive cultural resources in Gansu have not been changed into cultural industrialization yet. As far as the introduction of the regional culture to foreigners is concerned, Gansu lacks world-wide products except The Dream of Dunhuang, On the Silk Road, and others. Thus, those concerned in Gansu should be conscious of brand publicity and product marketing. They should be also active in publicizing their cultural products in order to attract more investors.

\section{Overlooking the Function of Predicting Assessment}

It is necessary to make a scientific and effective assessment for all the cultural resources in Gansu from the angles of culture, value, anticipation, inheritance, and so on. Special attention should be paid to those resources which are symbolic, representative, and large-scaled. The assessment should be done according to the following main elements: scarcity, oddity, scale, intactness, integration, and aesthetic value. The result of the assessment 
determines its development, marketing, products, and investment.

\section{Measures for the Industrialization of Regional Culture}

\section{From Cultural Resources to Cultural Capital}

Possessing rich cultural resources does not equal to enjoying the corresponding capital. More important is how to fully utilize them, develop their value, and make them develop sustainably. The inherent requirements of the industrialization of regional culture are to optimize the structure of production, change limited resources into unlimited capital, promote local economic growth, and improve the life of local citizens. The transformation of culture industry consists of three steps: (1) change cultural resources into visible products; (2) commercialize cultural products using the regional features; and (3) market the products in large scale with special methods for a better economic benefit (XIONG, 2012, p. 58; JIA, 2014). Gansu is very rich in cultural resources but poor in economy, which constraints its culture development. What the local government should do are: first, deeply study the cultural resources again in order to form a better cultural industry system; second, actively develop cultural products and attract investment; third and last, enhance the cooperation with cultural industry and other industries such as service, manufacture, and so on for an integrated development with a reasonable industrial chain. To cultural practitioners of Gansu, this is not only an opportunity but also a challenge.

\section{For a Better Regional Economic Development}

To a certain extent, culture industry is not only the catalyst of social economy but also the function of cultural economy. The requirements of cultural market in China are improving with obvious contemporaneity and regional significance. The unique regional culture is the outlet for the development of culture industry. Culture industry is a green one which is suitable for the new requirements of sustainable social development. It can relate to service, tourism, manufacturing, and so on, so as to improve the originality and connotation of its products. Its purpose is to stimulate domestic demand and consumption and to create new economic growing points from the angle of industrial development.

\section{Meeting the Spiritual Requirements of Local People}

Along with the rapid development of economy, the local people need more spiritual and cultural requirements, which is a very good opportunity for the cultural industrialization of Gansu. The cultural resources in Gansu are abundant but its development is poor and ineffective, keeping behind the requirements. The local government is required to make rapid progress in this field and make people change their consumption pattern and concept. In so doing, it is the proper way to make social and economic success.

\section{Sustainable Measures}

The notion of "sustainable development" came up with the discussion on the relationship between man and nature. It asks for the sustainable and harmonious development between economy, society, resources, and environment. The same problem also exists for the development of regional culture. It warns human to stop destroying nature. It is required to build up a favorable circle between resource and economy development. Concretely speaking, attention should be paid not only to economic benefit with limited cultural resources but also to sustainable development of regional culture, and so a long view is the wisest one. Cultural products are the special commodity in the ideological domain, so the effective route for the sustainable development is to link the economic value with the social value of cultural resources (KOU, 2016, pp. 1004-3381). Predatory 
exploitation will destroy the possibility for sustainable development of culture. The local government must adhere to sustainable development of the economic society and culture and should not think only of the present and neglect the future. Along with the rapid progress of new technology, it is possible to create new cultural activities, new forms, and new contents and media. All of them are the new resources of cultural industry. And as the exploiters of culture industrialization, they should energetically develop cultural industries, foster new cultural formats, and push cultural industries to become a pillar of our national economy.

\section{Conclusion}

Although Gansu is a big province rich in different types of historical and cultural resources, it has not become a big cultural province yet. Through this research, we have found that the industrialization of regional culture is not only a technical problem, but a social one. This is a problem which is worth thoroughly pondering and careful planning. The basis for the implementation of this task is the research of historical and cultural resources while cultural industrialization is its core. So, it should be led by the governments and carried out by universities and research units with planning and enough funds. What is of national is of international. Neither is it not fully characterized by regional culture nor economically effective, simply copying foreign ones. In the end, we could summarize that the industrialization of regional culture in Gansu need more attention to change concept, research, funds, and planning.

\section{References}

HUANG, F. J. (2014). A study on the government's role for the development of traditional cultural industrialization. Suzhou: Suzhou University.

JIA, X. D. (2014). Determining the new trend for the development of regional culture. China Culture Daily, 2014-09-03(006).

KOU, Y. (2016). A study on the development of cultural industry. People's Tribune, 5, 1004-3381.

TIAN, S. (2013). The rich connotation of historical and cultural resources in Gansu. Guangming Daily (Theoretic version), 2013-07-25(011).

XIONG, C. Y. (2012). The enlightenment of creative industry in UK. Seeking Truth, 7, 58. 